\title{
Study on the Cooperative E-commerce Model between Enterprises based on the Value Chain
}

\author{
XU Jun ${ }^{1,2}$ \\ ${ }^{1}$ School of Economics and Management, \\ Southeast University \\ ${ }^{2}$ Nanjing Special Education Normal College \\ 2493311507@qq.com
}

\author{
LIU Xiaoxing ${ }^{1}$ \\ ${ }^{1}$ School of Economics and Management, \\ Southeast University
}

\begin{abstract}
The real e-commerce between enterprises is based on the internal departments of enterprises and the cooperative interaction between enterprise and its partners. In this paper, on the basis of the theory of value chain, 11 cooperative e-commerce models between enterprises have been classified according to the activities of the cooperation between enterprises, and then every cooperative e-commerce model between enterprises is discussed. In practice, cooperative e-commerce between enterprises can be a combination of one or more e-commerce models between enterprises.
\end{abstract}

Keywords: E-commerce; Cooperative E-commerce; Cooperative Model; Value Chain

\section{Introduction}

E-commerce emerged in the early 1970 s, but has made a great achievement even though it developing period is not so long. At present, the B2B model has become the mainstream of e-commerce, accounting for $80 \%$ 90\% of the global e-commerce sales volume. B2B e-commerce includes three levels: (1) e-commerce centered at transactions gives top priority to the online transactions between enterprises and focuses on product trading itself, but not on relationship between buyers and sellers; (2) e-commerce centered at supply and demand gives top priority to the supply and demand relationship between enterprises and focuses on the production process and supply chain, but not only on product trading; (3) e-commerce centered at cooperation gives top priority to the cooperation between enterprises and focus on not only the production process and supply chain and also the overall optimization of the value chain in the virtual organizations of cooperative enterprises.

Cooperative e-commerce, as the highest level of B2B e-commerce development, is still in the stage of concept. Currently, there is no powerful, unified definition to cooperative e-commerce, because different researchers have different explanation to it based on a different angle. Gartner Group thinks that cooperative e-commerce is a new Internet-based e-commerce model allowing the cooperative interaction between the internal departments of enterprises, between enterprise and its business partners, or between the participants of trading community. Trade community can be composed of an industry, industrial branches or a supply chain. AMT thinks that the difference of cooperative e-commerce from the traditional e-commerce is that it emphasizes product research and development, production and manufacturing, product delivery, financial processing, and even the final performance evaluation so that all related parties can collaboratively, synchronously operate through the e-fair supporting the Internet.

Seen from the above definition, the core of the cooperative e-commerce is that cooperation can be implemented between the different internal departments of enterprises and between different 
enterprises, in order to achieve business objectives. Cooperation has been the core of cooperative e-commerce, which can be divided into the internal cooperation of enterprises and the cooperation between enterprises. Concerning about the collaborative model of cooperative e-commerce, scholars at home and abroad have made some studies in recent years, but they only make a preliminary classification from its concept. In this paper, from the perspective of value chain, the cooperative e-commerce model between enterprises is analyzed, trying to provide guidance for enterprises to make a choice and carry out cooperative e-commerce.

\section{The current situation of the study of cooperative e-commerce model}

Along with the development of e-commerce, many scholars at home and abroad have studied the collaborative model of cooperative e-commerce and raised different classifications from different angles. META Group (2000) divided cooperative e-commerce into design cooperative e-commerce, Market/Sellin cooperative e-commerce, buying cooperative e-commerce, and planning/forecasting cooperative e-commerce. Barratt (2004) divided supply chain cooperation into two types: longitudinal cooperation and horizontal cooperation. Longitudinal cooperation includes the cooperation between enterprise and suppliers and between customers and the internal functions of enterprise. Horizontal cooperation includes the cooperation between enterprise and its competitors and between other organizations and the internal functions of enterprise. Juan DU and Liyi ZHANG (2004) divided cooperative e-commerce into information cooperation, product production cooperation, product design cooperation, procurement cooperation, and forecast cooperation according to the concrete embodiment of cooperation. AMT (2003) divided cooperative e-commerce into cooperative design, cooperative commerce, and cooperative manufacturing according to the definition of cooperative e-commerce.
Cooperative design includes industrial design, engineering design, and industrial manufacturing. Business includes marketing, sales and logistics. Manufacturing includes material control, production planning, and cost control.

From the above analysis, it is known that e-commerce cooperation model has been not enough studied yet now. On this basis, in this paper, the cooperation model between e-commerce enterprises is studied from the perspective of value chain, and also 12 cooperation models between e-commerce enterprises as well as the corresponding value creation to each model are recognized.

\section{The recognition of the cooperative e-commerce models between enterprises based on value chain}

\subsection{Michael Porter's value chain theory}

Professor Porter, in his book Competitive Advantage, deeply analyzes all kinds of business activities and the interactive relationship between them, and proposes enterprise's value chain model. He divides enterprise's value activities into two types (basic activities and auxiliary activities). Basic activities are to directly create value, including stock logistics, manufacturing operations, shipping logistics, marketing, sales and after-sales service, etc. Auxiliary activities are to support value creation, including enterprise's infrastructure, human resource management, technology development, procurement activities, etc.

\subsection{Dividing the cooperative e-commerce models between enterprises based on value chain}

The traditional enterprise value chain theory is appropriate for analyzing the early enterprise behaviors and guiding the enterprise competition. However, along with the rapid progress of information technology, the in-depth and extensive development of e-commerce, and the increasing segmentation of the social division of labor, more and more enterprises choose a 
vertical specialized business strategy. Enterprises focus on the value activities they are the best at, while the value activities without an internal competitive advantage are done through cooperation or outsourcing.

Table 1: 11 types of e-commerce cooperation models recognized from the perspective of value chain

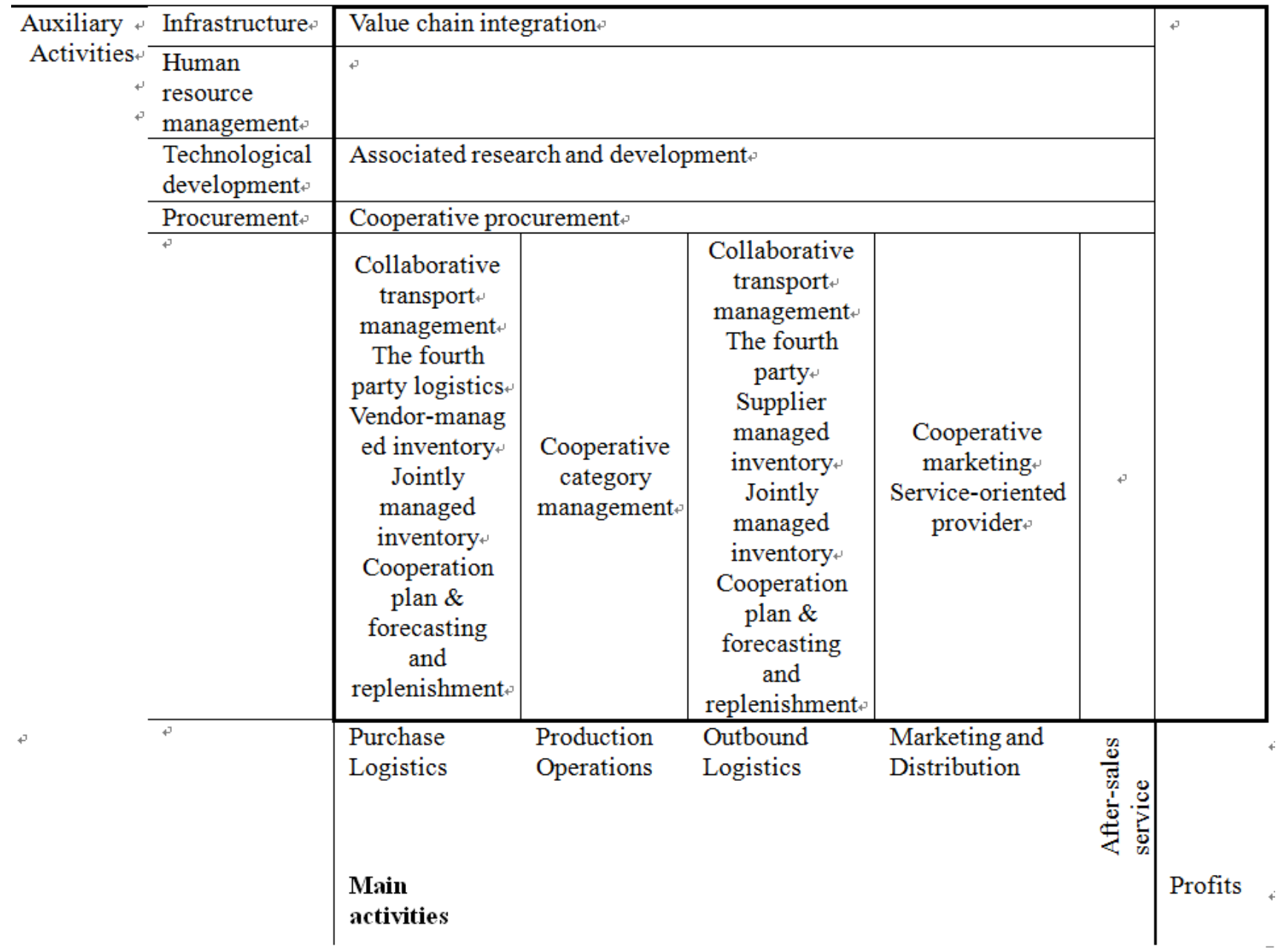

\section{(1) Value chain integrator}

The main role of value chain integrator is to coordinate the activities of the value chain. Value chain integrator usually collects, analyzes and comprehensively processes the forecasting, planning, production and operation information of upstream and downstream enterprises in the value chain, and then distributes it to related enterprises, in order to coordinate the operation of the participants in the value chain.

\section{(2) Research and development network integrator}

Technology development includes all kinds of efforts made to improve product and process.
Research and development are closely connected with engineering department and R\&D team. The design and research and development in the age of information often have multiple participants. Enterprises can integrate the research and development activities of their research and development partners on a global scale.

\section{(3) Cooperative procurement}

Enterprises as well as partners place the information about the raw materials and spare parts they need to purchase into the procurement platform for unified procurement, and suppliers also make transactions with manufacturers 
through this platform. Shared procurement platform can be dominated by the buyers, but also a third-party trading center.

(4) Collaborative transport management (CTM)

CTM is to gather the partners in the supply chain with transport service providers together and reach an agreement, aiming to avoid the inefficient operation in the process of transport planning and execution.

(5) The fourth party logistics (4PL)

The fourth party logistics participates in the logistics management, for the purpose of improving the efficiency and effectiveness of logistics. The fourth party logistics is dedicated to provide the activities such as logistics planning, consulting, logistics information system, and supply chain management, but does not undertake the specific logistics activities.

(6) Vendor managed inventory (VMI)

Vendor managed inventory is a model of inventory management cooperated by the upstream and downstream enterprises in the supply chain. On the basis of an agreement between both sides, the inventory management of downstream enterprises should be undertaken by the upstream enterprises. Upstream enterprises make forecasting and replenishment decisions by obtaining the downstream demand and inventory information.

(7) Joint management inventory (JMI)

Upstream and downstream enterprises are involved in the planning and management of inventory and centered at consumers. The two sides, on the basis of shared inventory information, jointly formulate the unified production plan and sales plan, and also hand over the plans to the corresponding manufacturing and sales departments to be implemented.

The transverse form of joint management inventory is shared inventory. That is, the enterprises in the same or similar business fields gather the inventory together and generate a shared inventory buffer pool, in order to implement unified purchasing, management, and deployment for the inventory of multiple enterprises.

(8) Cooperation plan \& forecasting and replenishment (CPFR)

Supplier and purchaser jointly make sales and order forecasting on the basis of the information about shared sales and inventory, and then make a joint replenishment plan.

(9) Cooperative category management

Cooperative category management is that retailers and suppliers jointly complete the category management tasks such as product classification, price formulation, shelf allocation, in-store promotion, and new products import and replenishment on the basis of shared POS data and the information on inventory levels. Sometimes, retailers focus on the core business, but outsource the non-strategic category management to suppliers.

(10) Cooperation sales

Sales are critical basic activities in the value chain. Enterprises and their competitors place their own products and services to sell on the shared sales platform, and then customers can buy products and services through the sales platform. From the perspective of the participants, a shared sales platform can be also a form of B2B.

\section{(11) Comprehensive service provider}

Comprehensive service provider is a form development from cooperative marketing. A wide range of related services can be provided by enterprises providing complementary products to customers within a certain area in the process of cooperative sales.

\section{Conclusion}

In this paper, 11 types of e-commerce cooperation models are recognized from the perspective of value chain. Enterprises can choose one or several of them as a combination when they are going to do e-commerce, to provide reference for others to use an e-commerce cooperation model. Of course, 11 types of e-commerce cooperation models recognized in this paper are impossible to cover 
all e-commerce models, because these models are presented in different forms in different industries and enterprises. Moreover, the problem of the combination between different models and the application condition and requirements of each model need to be further studied.

\section{Acknowledgement}

This paper aided financially by the general projects of the Natural Science Foundation of China (71273048).

\section{References}

[1] Junling XU, Tao WANG. Study on the CPFR-based Governance of the Relationship between Suppliers and Retailers [J]. Scientific Research Management, 2006 (2): 109-113.

[2] Xianghua FANG, Wenjie WANG, Bingyong TANG. Supply Chain Integration of New Technology [J]. Journal of Donghua University (Natural Science Edition), 2007 (2): 191-195.

[3] Li, J., Sikora, R., Shaw, M.J., Tan, G.W., (2006) A Strategic Analysis of Inter Organizational Information Sharing [J]. Decision Support Systems 42 (1), 251-266.

[4] Grean, M., and M.J. Shaw, (2000) Supply-Chain Integration through
Information Sharing: Channel Partnership between Wal-Mart and Procter \& Gamble, Center for IT and e-Business Management, University of Illinois at Urbana-Champaign, URL:

http://citebm.cba.uiuc.edu/IT-cases/Graen-S haw-PG.pdf (30.9.2002), 21 pp.

[5] Tyan, J. \& Wee, H.M. (2003).Vendor Managed Inventory: A Survey of the Taiwanese Grocery Industry [J]. Journal of Purchasing and Supply Management, 9:11-18.

[6] Kaipia, R., Tanskanen, K. (2003), Vendor Managed Category Management. An Outsourcing Solution in Retailing [J]. Journal of Purchasing \& Supply Management, 9:165-175.

[7] Lindblom, Arto and Olkkonen, Rami (2008). An Analysis of Suppliers' Roles in Category Management Collaboration [J]. Journal of Retailing and Consumer Services, Vol. 15, No. 1, pp1-8.

[8] Sari, K. (2008) on the benefits of CPFR and VMI: A Comparative Simulation Study [J]. International Journal of Production Economics, Vol. 113 No. 2, pp. 575-586.

[9] Gudmundsson, S.V. and Rhoades, D.L. (2001) Airline Alliance Survival Analysis: Typology, Strategy and Duration [J]. Transport Policy, 8 (3), pp. 209-218. 